Data de recebimento do artigo: $25-10-2017$

Data de aceite do artigo: $14-5-2018$

\title{
Do TEARS ao TEADI: Atributos importantes de blogueiras de moda para seguidores
}

\author{
Carla Fabrícia Abílio de Oliveira Gandra \\ Especialista em Gestão de Negócios pela Universidade Federal de Minas Gerais (UFMG) e Bacharel \\ em Secretariado. E-mail: carlagandra@gmail.com (Brasil) \\ Marlusa de Sevilha Gosling \\ Pós-doutora em Gestão de Turismo pela Universidade do Algarve, Portugal. Orientadora de mestrado \\ e doutorado, coordenadora do Núcleo de Estudos e Estratégias de Comunicação Integrada de \\ Marketing e Turismo - NEECIM-TUR-UFMG. \\ E-mail: mg.ufmg@gmail.com (Brasil) \\ Luciana Alves Rodas Vera \\ Doutoranda em Administração na Universidade Federal de Minas Gerais (UFMG). \\ E-mail: lu.alvesvera@gmail.com (Brasil)

\section{Bruno de Almeida Vilela} \\ Doutorando em Administração na Universidade Federal de Minas Gerais (UFMG). \\ E-mail: brunoavilela@gmail.com (Brasil)
}

\section{RESUMO}

Os blogs de moda têm se destacado pelo poder de influenciar os seguidores e por modificar o estilo de vida e de consumo das pessoas. O objetivo deste estudo é verificar quais são os atributos importantes das blogueiras de moda que contribuem para a intenção das pessoas de continuarem seguindo os blogs. Nesse sentido, este estudo propõe um modelo teórico no intuito de avaliar a relação entre os atributos importantes de blogueiras de moda e a intenção das pessoas de continuarem seguindo os blogs. A partir da análise fatorial exploratória, foram identificados cinco fatores relevantes: Confiabilidade, Expertise, Atração Física, Similaridade e Difusão da Informação e Ideias. A análise de modelagem de equações estruturais revelou que as variáveis independentes "Difusão de Informação e Ideias, Similaridade e Atração Física" têm relação positiva direta com a intenção de continuar seguindo, enquanto a Confiabilidade, a Expertise e o Respeito não foram hipóteses suportadas no estudo.

Palavras-chave: Blogs de moda. Modelo TEARS. Endossantes de marca. 


\title{
From TEARS to TEADI: Important attributes of fashion bloggers for followers
}

\begin{abstract}
Fashion blogs have stood out for the power to influence followers and for changing people's lifestyle and consumption habits. The objective of this study is to verify the important attributes of fashion bloggers that contribute to the intention of people to continue following the blogs. In this sense, this study proposes a theoretical model in order to evaluate the relationship between the important attributes of fashion bloggers and the people's intention to continue following the blogs. From the exploratory factorial analysis, five relevant factors were identified: Reliability, Expertise, Physical Attraction, Similarity and Diffusion of Information and Ideas. The modeling analysis of structural equations revealed that the independent variables Diffusion of Information and Ideas, Similarity and Physical Attraction have a direct positive relation with the intention to continue following, while Reliability, Expertise and Respect were not hypotheses supported in the study.
\end{abstract}

Keywords: Fashion blogs. TEARS Model. Brand Endorsers.

\section{Como referenciar em APA:}

Gandra, C. F. A. O., Gosling, M. S., Vera, L. A. R., Vilela, B. A. (2018). Do TEARS ao TEADI: Atributos importantes de blogueiras de moda para seguidores. R.G.Secr.,GESEC, 9(3).

\section{Como referenciar em ABNT:}

GANDRA, C. F. A. O.; GOSLING, M. S.; VERA, L. A. R.; VILELA, B. A. (2018). Do TEARS ao TEADI: Atributos importantes de blogueiras de moda para seguidores. R.G.Secr.,GESEC, v. 9, n. 3, Dez. 2018.
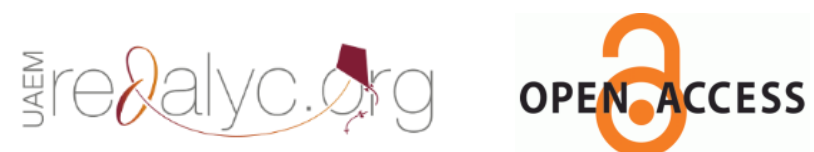


\section{Introdução}

Novos formatos de comunicação, compartilhamento e desenvolvimento de conhecimento entre indivíduos, organizações e comunidades têm sido potencializados pelas mídias sociais, que correspondem a uma "categoria de mídia online, na qual o conteúdo é criado pela sua audiência, por meio da participação e do compartilhamento do conteúdo gerado pelos usuários na forma de rede" (Kaplan \& Haenlein, 2010, p. 61). A pesquisa "Futuro Digital em Foco Brasil 2015" (Comscore, 2015) indicou que os brasileiros são líderes no tempo gasto nas mídias sociais. Conforme o estudo, a média do Brasil é $60 \%$ maior do que a do resto do planeta.

Dentre os variados tipos de mídias sociais, é possível destacar os blogs, atualizados por posts, que podem incluir textos, artigos, links, fotografias ou vídeos. A fácil utilização dessa ferramenta de publicação justifica a produção de conteúdos muito variados, destinados a públicos específicos, que é o que o está tornando mais popular e assumindo maior importância no mundo dos negócios. Um sinal dessa influência é a visível popularização dessa mídia independente em vários segmentos, fornecendo informação, aprimorando conceitos e gerando referências, por exemplo, no mercado da moda. Os $b \log _{s}$ de moda têm se destacado dentre os outros blogs, não apenas pelo poder de influenciar os leitores, mas também por modificar o estilo de vida das pessoas (Leitão, 2009).

Tendo em vista a popularidade que os blogs de moda têm adquirido atualmente, a pergunta de pesquisa que norteia este trabalho é: quais são os principais atributos das blogueiras de moda, na perspectiva de seus (suas) seguidores (as), que têm relação com a intenção das pessoas em continuarem seguindo os blogs? Portanto, o objetivo principal do presente trabalho é o de verificar quais são os atributos importantes das blogueiras de moda que contribuem para a intenção das pessoas de continuarem seguindo os blogs. Nesse sentido, o artigo propõe um modelo teórico que avalia a relação entre os atributos importantes de blogueiras de moda e a intenção das pessoas de continuarem seguindo os blogs.

A justificativa para este estudo se dá pelo crescimento nos últimos anos dos blogs de moda como um espaço para se analisar, comentar e divulgar assuntos relacionados à moda (Sarturi \& Cerqueira, 2017). De acordo com Schneider e Pereira (2015), o sucesso tem sido tão grande que a credibilidade dos blogs de moda tem superado a da mídia tradicional e a 
opinião das blogueiras de moda possui a mesma importância que a de um/a crítica/o de jornal ou revista. Conforme os autores, a audiência pode ser maior que a do segmento especializado. Assim, o motivo de este artigo dedicar atenção à temática dos atributos das blogueiras de moda e da intenção das pessoas em continuar seguindo os blogs de moda se deu pelo potencial destes serem endossantes de marca e influenciadores do comportamento do consumidor em relação a diversos segmentos do varejo, como roupas, calçados, produtos de beleza, entre outros.

Para entender os principais atributos, foi realizada uma pesquisa baseada nos cinco componentes do modelo teórico desenvolvido por Shimp (2009), denominado Modelo TEARS (Trustworthiness, Expertise, Attractiveness, Respect e Similarity, isto é, Confiabilidade, Expertise, Atração, Respeito e Similaridade). Além disso, foi incorporado ao modelo mais um constructo denominado Difusão da Informação e de Ideias, baseado no estudo de Clarke e Johnstone (2012).

\section{Referencial Teórico}

\section{Blogs e blogs de moda}

Em constante crescimento na sociedade contemporânea, as mídias sociais correspondem a um fenômeno mundial revelado nos últimos anos bastante importante no contexto da comunicação social e da disseminação do conhecimento. Segundo Kaplan e Haenlein (2010), as mídias sociais são um grupo de aplicações na internet que permitem a criação e a troca de conteúdo gerado pelos usuários. Elas adotam formas diferentes como wikis, sites de redes sociais (como o Facebook), sites de compartilhamento de mídia (a exemplo do Instagram e do YouTube), sites de avaliação (como o TripAdvisor) e blogs.

Huang, Shen, Lin \& Chang (2007) definem os blogs como "diários pessoais na internet dispostos em sequência cronológica inversa que facilitam a comunicação interativa mediada por meio de textos, imagens e áudio/vídeo" (p. 473). Embora os primeiros blogs datem do final da década de 1990 (Dearstyne, 2005), os blogs tornaram-se uma ferramenta popular para as comunicações interativas mediadas por computadores durante os últimos anos. 
Os blogueiros são pessoas influentes que postam suas ideias online (Zanette, 2012) e tendem a reunir seus seguidores em torno de suas personas, sendo considerados líderes de opinião, que realizam conversas em seus espaços online (Zanette, Brito \& Coutinho, 2013). Dentre os variados tipos de blogs existentes, têm ganhado destaque os blogs de moda, que estão se tornando rapidamente uma força influente dentro da indústria da moda. Para Clarke e Johnstone (2012), eles têm se tornado uma importante ferramenta no contexto da indústria fashion, porque os blogueiros de moda têm usado o poder da comunicação boca a boca online (e-Word-of-Mouth) para espalhar suas opiniões sobre as marcas e as empresas para os seus leitores.

Kent (2008) identifica três pontos fortes dos blogs. O primeiro descreve a sua capacidade de conectar as pessoas com interesses semelhantes através da Internet. Em segundo lugar, os leitores de blogs podem se comunicar com o blogueiro e outros leitores do blog, demonstrando assim o elemento interativo dos blogs e seus potenciais como a comunicação boca-a-boca online. Por último, em terceiro lugar, para Kent (2008), os blogs têm o poder de "alcançar o coro". Como as pessoas têm acessado bastante os blogs, é provável que essas pessoas sejam indivíduos que têm interesses ou visões de mundo semelhantes (Kent, 2008).

De acordo com Kent (2008), tais pontos fortes dos blogs ilustram por que as organizações devem prestar mais atenção a tal mídia social, se elas querem influenciar líderes de opinião. No entanto, poucas pesquisas têm se voltado para a influência dos blogueiros de moda para os consumidores, e sua adoção das tendências da moda (Clarke \& Johnstone, 2012).

Em um estudo feito com o objetivo de compreender como os blogueiros de moda influenciam as atitudes e as opiniões dos seus leitores, Clarke e Johnstone (2012) conduziram uma pesquisa qualitativa, cujos resultados revelaram que alguns blogs podem ser visto como "hubs" (cabos) que operam no âmbito da rede de blogs de moda. Nesta rede, acontece a difusão de informação e ideias, semelhante à difusão de um produto dentro do mercado. Em segundo lugar, os autores concluíram que os blogs de moda são mais propensos a serem influentes no nível coletivo, em vez de no nível individual, assim como o comportamento de compra e a adoção de tendência não são resultados da leitura de um blog, mas de vários blogs. Por fim, Clarke e Johnstone (2012) notaram que os blogs de moda eram frequentemente 
utilizados para comparações sociais na gestão do autoconceito dos pesquisados e para evitar a adoção de uma tendência que pode ser associada a um grupo indesejável.

\section{Atributos dos endossantes: o modelo TEARS e o construto difusão de informação e ideias}

De acordo com Falsarella, Oliveira e Giraldi (2017), uma parcela significativa dos recursos financeiros das empresas é voltada para as campanhas publicitárias, em busca de atrair a atenção dos consumidores para seus produtos e marcas e influenciar seu valor de mercado. Nesse sentido, no intuito de criar um impacto positivo e um retorno financeiro maior, as empresas adicionam o endosso de celebridades a campanhas publicitárias, ou seja, o uso de celebridades com qualidades atraentes que são reconhecidas e admiradas pela sociedade (Falsarella, Oliveira \& Giraldi, 2017). McCracken (1989) define um endossante de celebridade como uma ferramenta onipresente do marketing moderno e como "qualquer indivíduo que goza de reconhecimento público e que usa esse reconhecimento em nome de um bem de consumo ao aparecer com ele em uma propaganda" (p. 310). Já Friedman e Friedman (1979) afirmam que o endossante de marca corresponde a um indivíduo conhecido do público (como atores, apresentadores de TV, cantores, entre outros) por sua relevância em diversos campos diferentes dos quais estão os produtos/serviços por eles endossados.

Para Freire, Behling e Reinert (2010), muitas pessoas enxergam o estilo de vida das celebridades/endossantes como uma fórmula de sucesso e procuram seguir o seu comportamento. Na visão dos autores, tal conduta pode estar atrelada ao fato de a celebridade ser uma pessoa com inúmeros atributos, tais como: inteligência, beleza e carisma, sendo reconhecida pelo público e considerada como exemplo a ser seguido. Consequentemente, a imagem dos endossantes pode influenciar o comportamento de compra do consumidor. Os endossantes de marca e seus atributos já foram objeto de alguns estudos. Nesse sentido, a Figura 1 apresenta alguns destes trabalhos:

Figura 1 - Estudos voltados para a temática dos endossantes de marca.

\begin{tabular}{|l|l|l|}
\hline Autor & Constructos estudados & Principais resultados \\
\hline $\begin{array}{l}\text { Ohanian } \\
(1991)\end{array}$ & $\begin{array}{l}\text { A autora desenvolveu uma escala para medir a } \\
\text { credibilidade da celebridade em três } \\
\text { dimensões: confiabilidade, atratividade e e }\end{array}$ & $\begin{array}{l}\text { A atratividade e a confiabilidade não } \\
\text { tiveram impacto sobre a intenção de } \\
\text { compra, mas a expertise teve um impacto }\end{array}$ \\
\hline
\end{tabular}




\begin{tabular}{|c|c|c|}
\hline & expertise. & significante. \\
\hline $\begin{array}{l}\text { Goldsmith, } \\
\text { Lafferty e } \\
\text { Newell (2000) }\end{array}$ & $\begin{array}{l}\text { O estudo teve o objetivo de verificar a } \\
\text { credibilidade do endossante, a atitude do } \\
\text { consumidor em relação à propaganda, a } \\
\text { credibilidade da organização, a atitude em } \\
\text { relação à marca e as intenções de compra. }\end{array}$ & $\begin{array}{l}\text { A credibilidade da organização tem } \\
\text { impacto positivo nas atitudes dos } \\
\text { consumidores no que diz respeito à } \\
\text { propaganda, marca e intenção de compra. } \\
\text { A credibilidade do endossante, por outro } \\
\text { lado, funciona somente através do seu } \\
\text { impacto na propaganda. }\end{array}$ \\
\hline $\begin{array}{l}\text { Hakimi, } \\
\text { Abedniya e } \\
\text { Zaeim (2011) }\end{array}$ & $\begin{array}{llll}\text { Os autores } & \text { estudaram } & \text { o } & \text { constructo } \\
\text { confiabilidade. } & & & \end{array}$ & $\begin{array}{l}\text { A confiabilidade não foi um fator para a } \\
\text { intenção dos consumidores em tentarem } \\
\text { uma marca. }\end{array}$ \\
\hline $\begin{array}{l}\text { Ladeira, } \\
\text { Araújo, } \\
\text { Santini \& \& } \\
\text { Henz (2015) }\end{array}$ & $\begin{array}{l}\mathrm{O} \text { artigo teve como objetivo analisar a } \\
\text { influência dos atributos de celebridades do } \\
\text { futebol na intenção de compra de chuteiras. Os } \\
\text { construtos estudados foram: Habilidade do } \\
\text { jogador, Carisma do Jogador, Posição em que } \\
\text { joga, Status da marca que usa, } \\
\text { Profissionalismo do jogador, Postura do } \\
\text { Jogador, Imagem do jogador, Histórico do } \\
\text { jogador, Imagem no clube, e Imagem na } \\
\text { seleção. }\end{array}$ & $\begin{array}{l}\text { Os resultados evidenciaram que não existe } \\
\text { significância estatística entre a intenção de } \\
\text { compra de chuteira e os atributos dos } \\
\text { endossantes: postura, imagem, histórico, } \\
\text { clube em que joga e o fato de ser jogador } \\
\text { de seleção. Os atributos dos endossantes } \\
\text { que influenciaram a intenção de compra } \\
\text { foram: carisma, uso de marca famosa, } \\
\text { posição que joga, habilidade e } \\
\text { profissionalismo. Constatou-se que os dois } \\
\text { últimos exercem uma influência inversa. } \\
\text { No caso de uma relação direta mais forte } \\
\text { esta foi evidenciada no atributo carisma. }\end{array}$ \\
\hline
\end{tabular}

Fonte: Ohanian (1991), Goldsmith, Lafferty e Newell (2000), Hakimi, Abedniya e Zaeim (2011), e Ladeira et al. (2015)

No presente artigo, como fundamentação teórica, foi utilizado o modelo teórico proposto por Shimp (2009). Tal autor indicou que os dois atributos gerais Credibilidade e Atratividade contribuem para a eficiência do endossante, e que cada um desses atributos é formado por subatributos mais distintos. Para facilitar a memorização das características do endossante, Shimp (2009) utiliza o acrônimo TEARS para representar os cinco atributos discretos em seu modelo teórico. A Confiabilidade (Trustworthness) e o Conhecimento Específico (Expertise) são duas dimensões da Credibilidade, enquanto a Atração Física (Physical Attractiveness), o Respeito (Respect) e a Similaridade (Similarity - com o públicoalvo) são componentes do conceito geral da Atratividade. Em sintonia com Shimp (2009), Sheu (2010) observa que o endosso de uma celebridade particular tem a ver com a sua credibilidade e a sua atratividade para criar familiaridade, similaridade e gostos. 
Figura 2 - Os parâmetros do Modelo TEARS, proposto por Shimp (2009) e adaptação do modelo TEARS para o uso nesta pesquisa.

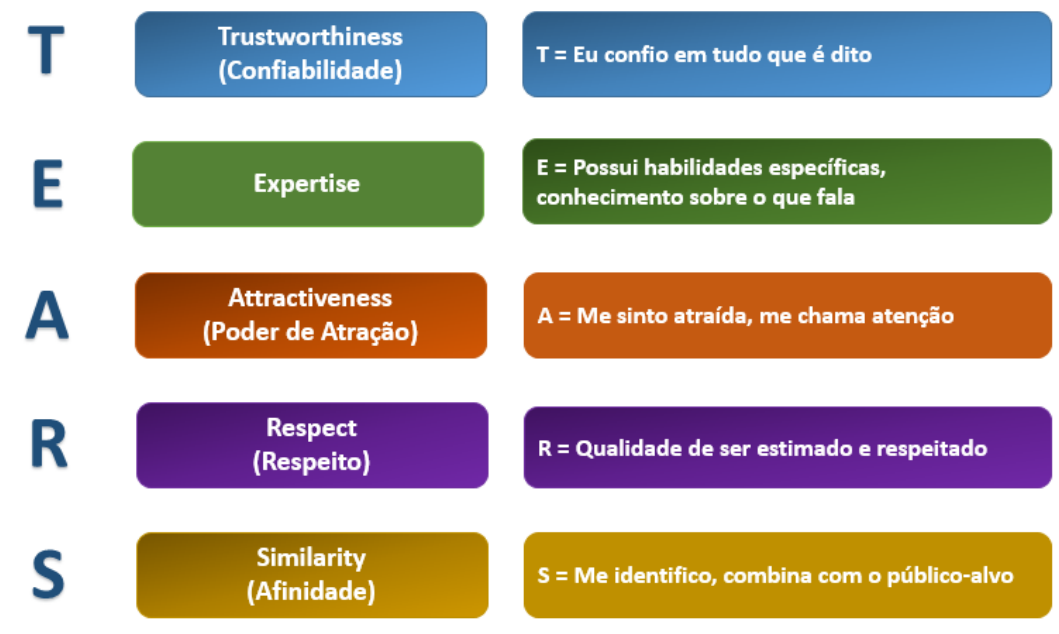

Fonte: Shimp (2009).

A Credibilidade está relacionada à tendência de acreditar ou confiar em alguém (Shimp, 2009). Para o autor, quando uma fonte de informação, como um endossante, é percebida como confiável, as atitudes do público se alteram através de um processo psicológico, chamado interiorização. Tal processo ocorre quando o receptor aceita a posição do endossante sobre uma questão como se fosse sua opinião. Isso apresenta sintonia com a visão de Erdogan e Baker (2000) que indicam que, entre as razões para usar celebridades/influenciadores na publicidade, estão a capacidade dessas pessoas de transferir valor para a marca; maior credibilidade da marca por associação com figuras conhecidas; e maior atenção do consumidor quando há a presença da personalidade em meio a um grande número de mensagens promocionais. Para Alsmadi (2006), a credibilidade deve ser considerada como a mais importante razão para selecionar uma celebridade.

Shimp (2009) aponta a Confiabilidade e o Conhecimento Específico como dois subatributos importantes da Credibilidade. A Confiabilidade está relacionada com a honestidade, integridade e credibilidade de uma fonte (Shimp, 2009; Waldt, Van Loggerenberg \& Wehmeyer, 2009). Apesar da Confiabilidade e do Conhecimento Específico não serem mutuamente exclusivos, em geral determinado endossante é percebido como altamente confiável, mas não muito conhecedor. A Confiabilidade no endossante, de acordo com o autor, reflete apenas o fato de que os possíveis endossantes de uma marca são 
diferentes em termos do grau em que os integrantes do público confiam no que eles têm a dizer. Em sintonia com Shimp (2009), Ali (2011) explica que, quando o endossante é percebido como confiável, quer dizer que ele é visto como honesto, de maneira que os consumidores acreditam nele. Para Shimp (2009), a Confiabilidade dos endossantes depende da percepção por parte do público de suas motivações de endosso. Assim, se os consumidores acreditarem que um endossante está motivado unicamente por interesses pessoais, esse endossante será menos persuasivo do que outra pessoa considerada como não tendo nada a ganhar com o endosso da marca. Desta discussão, propõe-se a hipótese 1:

Hipótese 1: A Confiabilidade tem relação direta e positiva com a intenção de continuar seguindo.

O Conhecimento Específico (Expertise) está relacionado, segundo Shimp (2009), ao conhecimento, experiência ou habilidades de um endossante, em relação à marca endossada. Tal definição corrobora o que Erdogan (1999) afirmou sobre o Conhecimento Específico como sendo o grau em que um comunicador é percebido como uma fonte de informações válidas, alicerçada no conhecimento ou na experiência. Para Ali (2011), o endossante é considerado como especialista quando demonstra ter habilidades e conhecimentos específicos no que diz respeito à marca endossada. O conhecimento é um fenômeno percebido e não absoluto. Shimp (2009), por outro lado, explica que o fato de um endossante ser realmente um especialista não é importante e sim como o público percebe o endossante é o que importa. Assim, um endossante percebido como um expert em determinado assunto é mais convincente para mudar as opiniões do público relacionadas às suas áreas de atuação, do que um endossante que não é percebido como especialista. Neste sentido, a hipótese 2 foi proposta:

Hipótese 2: O Conhecimento Específico tem relação direta e positiva com a intenção de continuar seguindo.

A atratividade envolve qualquer quantidade de características virtuosas, que os consumidores possam perceber em um endossante. Pode ser desempenho intelectual, 
propriedades da personalidade, características do estilo de vida, porte atlético, entre outros. Para Shimp (2009), a Atração Física é um importante aspecto em vários relacionamentos com o endosso. Os endossantes fisicamente atraentes geram avaliações mais favoráveis no anúncio e nas marcas anunciadas, conforme o autor. Na visão de Patel (2009), a celebridade escolhida deve ser bonita e atraente. Felix e Borges (2014) sugerem que uma análise da atratividade do endossante precisa buscar entender qual é a atenção visual dirigida para ele. Embora a atenção seja um primeiro passo crucial em qualquer resposta positiva do consumidor, eles indicam que é um antecedente importante, mas comumente negligenciado, em estudos de modelos de propaganda de hierarquia clássica de efeitos sobre a atratividade do endossante. A partir disso, a hipótese 3 foi definida:

Hipótese 3: A Atração Física tem relação direta e positiva com a intenção de continuar seguindo.

O Respeito representa a qualidade de ser admirado e até estimado por causa das qualidades e realizações pessoais de alguém. Shimp (2009) explica que a Atratividade Física pode ser considerada o aspecto "forma", enquanto que o respeito pode representar a "função" ou o elemento sério. Em conformidade com Shimp (2009), Ali (2011) expõe que o respeito corresponde a quando o endossante é percebido pelas pessoas com admiração. Por isso, propõe-se a hipótese 4:

Hipótese 4: O Respeito tem relação direta e positiva com a intenção de continuar seguindo.

Já a Similaridade representa o nível até onde o endossante combina com o público em termos das características pertinentes à relação do endosso - idade, sexo, etnia, entre outros aspectos. A Similaridade é um atributo importante pelo simples fato de que as pessoas tendem a aprovar mais quem compartilha com elas algumas características ou aspectos em comum (Shimp, 2009). Pringle e Binet (2005) definiram as celebridades dentro do escopo de marketing como alguém familiarizado o suficiente para agregar valor à comunicação e ao processo de identificação de marca associando sua imagem e reputação. 
Hipótese 5: A Similaridade tem relação direta e positiva com a intenção de continuar seguindo.

Tendo o modelo TEARS como base teórica, Barbosa, Kovacs, Farias, Melo e Souza, A. G (2014) realizaram um estudo qualitativo com o objetivo analisar as características de credibilidade e atratividade dos endossantes de blogs de moda na visão das seguidoras. Os autores fizeram entrevistas com oito seguidoras e verificaram que os atributos presentes no modelo TEARS foram identificados nas entrevistas. As leitoras consideraram que a Confiabilidade, a Similaridade e o Respeito são os atributos mais relevantes para a legitimação das blogueiras de moda (Barbosa et al., 2014).

O Conhecimento Específico também foi visto como importante pelas seguidoras, já que elas afirmaram que deve existir uma sintonia entre a marca e a blogueira que atua como endossante, ao mesmo tempo em que esta deve possuir um discurso coerente e autônomo (Barbosa et $a l ., 2014)$. A Atração Física foi outro construto considerado essencial pelas entrevistadas por causa do contexto em que as blogueiras de moda estão inseridas no qual a imagem é bem valorizada.

Clarke e Johnstone (2012), em sua pesquisa sobre a forma como blogueiros de moda influenciam as atitudes e opiniões dos seus leitores, verificaram que acontece, dentro da rede de $b \log s$, a difusão de informações e ideias, de maneira similar à difusão de um produto dentro do ambiente de mercado. Para os autores, os blogs mais populares podem ser vistos como conectores porque eles são os primeiros a difundir tendências de moda por meio da blogosfera. Clarke e Johnstone (2012) apontam o poder dos blogueiros de moda que, como líderes de opinião, podem ser muito influentes durante o processo de difusão de um produto. Em virtude de a Difusão de Informações e Ideias ser apontada como um atributo importante dos blogueiros de moda, tal construto foi incorporado neste estudo.

Hipótese 6: A Difusão de Informações e Ideias tem relação direta e positiva com a intenção de continuar seguindo. 
Figura 3 - Modelo proposto pelos autores.

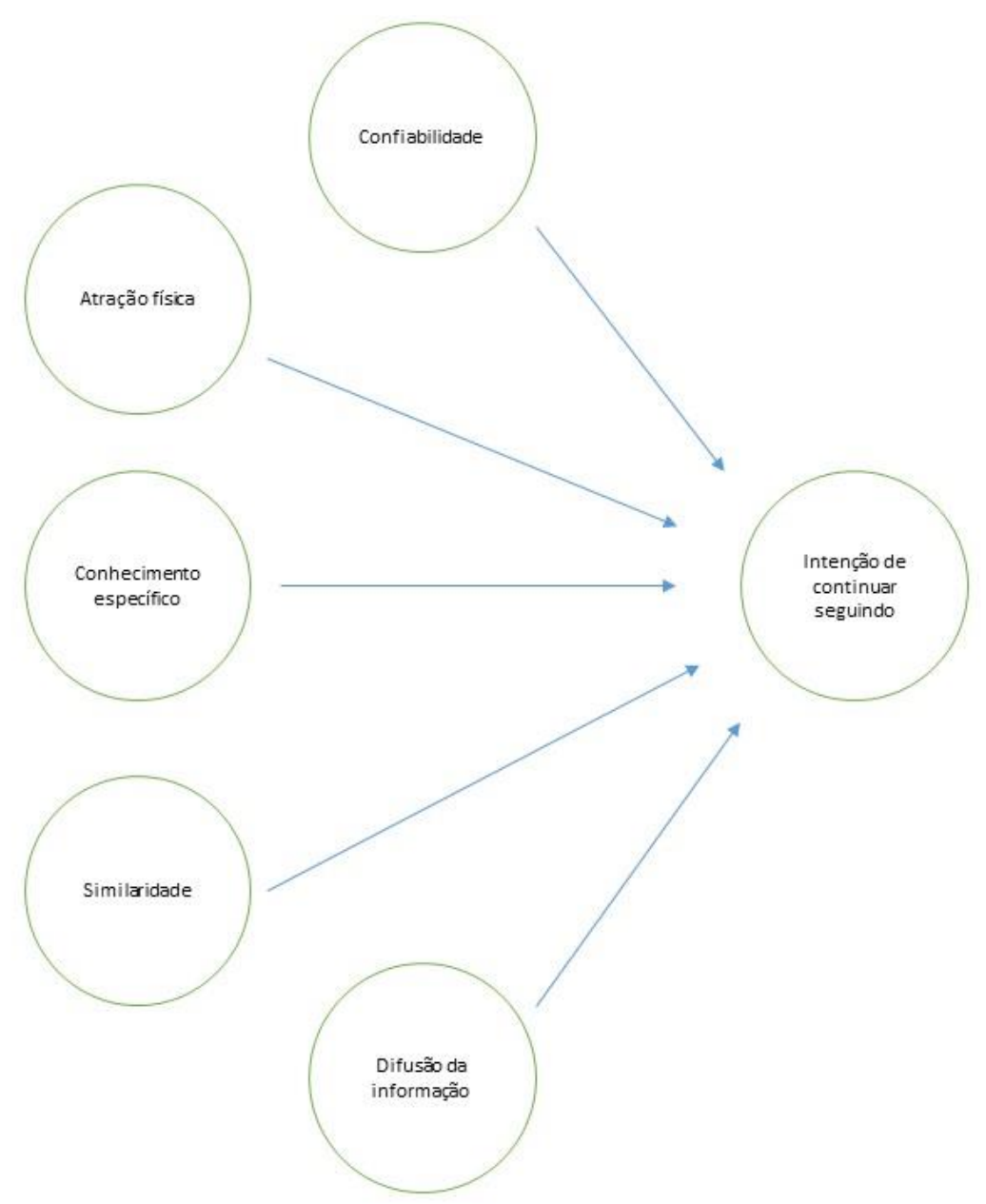

Fonte: Dados do estudo, 2018.

Figura 4 - Síntese das hipóteses elaboradas a partir da adaptação do modelo TEARS, proposto por Shimp (2009), e do construto Difusão de Informações e Ideias, proposto por Clarke e Johnstone (2012).

\begin{tabular}{|l|l|}
\hline Hipóteses & \\
\hline H1 & A Confiabilidade tem relação direta e positiva com a intenção de continuar seguindo. \\
\hline H2 & A Expertise tem relação direta e positiva com a intenção de continuar seguindo. \\
\hline H3 & A Atração Física tem relação direta e positiva com a intenção de continuar seguindo. \\
\hline H4 & O Respeito tem relação direta e positiva com a intenção de continuar seguindo. \\
\hline H5 & A Similaridade tem relação direta e positiva com a intenção de continuar seguindo. \\
\hline H6 & A Difusão de Informações e Ideias tem relação direta e positiva com a intenção de continuar seguindo. \\
\hline
\end{tabular}




\section{Metodologia}

O presente trabalho corresponde a uma pesquisa exploratória com seguidores (as) de blogs de moda e beleza, cuja abordagem é quantitativa. No que se refere à coleta de dados, foi realizado um survey. A amostra utilizada foi do tipo não probabilística por conveniência. De acordo com Anderson, Sweeney e Williams (2007), as amostras por conveniência têm a vantagem de permitir que a escolha de amostras e a coleta de dados sejam relativamente fáceis. A amostra foi formada por 259 indivíduos que declararam seguir blogs de moda.

Os itens do questionário foram desenvolvidos com base na ideia trazida pelos constructos do modelo TEARS, desenvolvido por Shimp (2009), e nos resultados do estudo qualitativo exploratório de Barbosa et al. (2014) e de Clarke e Johnstone (2012). Como o modelo teórico proposto por Shimp (2009) não oferece propriamente itens para um questionário, os autores do presente artigo utilizaram os resultados da análise das entrevistas da pesquisa de Barbosa et al. (2014) sobre atributos importantes de blogueiras de moda como base para construir as escalas do instrumento de coleta de dados. Trata-se, portanto, de um estudo exploratório, porque não foram feitos estudos anteriores com propostas de escalas para o modelo TEARS de Shimp (2009). Além disso, o presente trabalho propôs a inclusão de uma variável ao modelo TEARS (Difusão de Informação e de Ideias), ampliando-o.

Para fazer a validação do instrumento de coleta de dados, foi feita uma etapa com painel de especialistas. No total, cinco especialistas - pesquisadores seniores de marketing digital/professores doutores de Instituições Federais de Ensino Superior - participaram do processo. Foram apresentados extratos dos itens criados pelos estudos de Barbosa et al. (2014) e de Clarke e Johnstone (2012) e os atributos de Shimp (2009), solicitando que cada especialista, sem contato com os demais, fizesse a ligação entre essas partes e os itens criados. Apenas os itens coincidentes entre os especialistas permaneceram no instrumento final.

Uma vez validados pelos especialistas, para a mensuração das variáveis (itens) presentes no questionário, escolheu-se a utilização de escala intervalar do tipo Likert de 10 pontos, variando de "Pouco importante" (0) a "Muito importante" (10). O questionário foi disponibilizado na plataforma Google Docs e divulgado através de um link em mídias sociais como Facebook. 
No Quadro 1, apresentam-se os construtos e os itens do questionário oriundos dos subatributos descritos por Shimp (2009) e por Clarke e Johnstone (2012). Assim, o presente trabalho propõe uma ampliação do modelo TEARS para a inclusão do constructo Difusão de Informação e de Ideias (D), formando, portanto, o modelo TEARSD.

Figura 5 - Construtos elaborados a partir do modelo TEARS (Shimp, 2009) e de Clarke e Johnstone (2012).

\begin{tabular}{|c|c|c|}
\hline Construto & Perguntas & Base teórica \\
\hline \multirow{12}{*}{ Confiabilidade } & Para você se tornar seguidor (a), uma blogueira de moda ..... & Autores \\
\hline & CONF 1. postar algo que faz você acreditar no que foi dito & \multirow{11}{*}{$\begin{array}{l}\text { Shimp (2009); } \\
\text { Barbosa et al. } \\
\text { (2014) }\end{array}$} \\
\hline & CONF 2. ter posições/opiniões muito parecidas com as suas & \\
\hline & CONF 3. não ter publiposts (posts publicitários) & \\
\hline & $\begin{array}{l}\text { CONF 4. em geral, promover uma quantidade de marcas/produtos aceitável (não é } \\
\text { exagerada) }\end{array}$ & \\
\hline & CONF 5. não estar motivada apenas por interesses pessoais ao promover uma marca/produto & \\
\hline & CONF 6. passar credibilidade & \\
\hline & CONF 7. não manipular os seguidores, ser íntegra & \\
\hline & CONF 8. ser objetiva em seus posts & \\
\hline & CONF 9. ser confiável & \\
\hline & CONF 10. ser honesta & \\
\hline & CONF 11. ser íntegra & \\
\hline \multirow{11}{*}{$\begin{array}{c}\text { Expertise / } \\
\text { Conhecimento }\end{array}$} & Para você se tornar seguidor (a), uma blogueira de moda ..... & Autores \\
\hline & EXP 1. possuir conhecimento sobre o que publica & \multirow{10}{*}{$\begin{array}{l}\text { Shimp (2009); } \\
\text { Barbosa et al. } \\
\text { (2014) }\end{array}$} \\
\hline & EXP 2. ser experiente quanto ao que publica & \\
\hline & $\begin{array}{l}\text { EXP 3. ser especialista nas marcas/produtos que promove/estar familiarizada com as } \\
\text { marcas/produtos que promove }\end{array}$ & \\
\hline & EXP 4. ser inteligente & \\
\hline & EXP 5. ter personalidade atraente & \\
\hline & EXP 6. ter um estilo de vida diferenciado, estimulante & \\
\hline & EXP 7. estar familiarizada com as marcas/produtos que promove & \\
\hline & EXP 8. conhecer a fundo escolhas e referências de estilistas & \\
\hline & EXP 9. ser especialista nas marcas/produtos sobre as quais publica & \\
\hline & EXP 10. publicar sobre marcas/produtos que ela gosta ou se identifica & \\
\hline \multirow{6}{*}{ Atração Física } & Para você se tornar seguidor (a), uma blogueira de moda ..... & Autores \\
\hline & AF 1. ser bonita & \multirow{5}{*}{$\begin{array}{l}\text { Shimp (2009); } \\
\text { Barbosa et al. } \\
(2014)\end{array}$} \\
\hline & AF 2. ter uma boa apresentação pessoal & \\
\hline & AF 3. chamar muito a atenção para tudo que anuncia & \\
\hline & AF 4. ficar bem (em termos de aparência) vídeos & \\
\hline & AF 5. seguir o padrão de beleza imposto pela mídia & \\
\hline \multirow{8}{*}{ Respeito } & Para você se tornar seguidor (a), uma blogueira de moda ..... & Autores \\
\hline & RESP 1. ser admirada pelo trabalho & \multirow{7}{*}{$\begin{array}{l}\text { Shimp (2009); } \\
\text { Barbosa et al. } \\
(2014)\end{array}$} \\
\hline & RESP 2. ser admirada pelo estilo de vestir & \\
\hline & RESP 3. trabalhar bastante para serem conhecidas & \\
\hline & RESP 4. ser criativa & \\
\hline & RESP 5. saber se diferenciar & \\
\hline & RESP 6. conseguir que você se identifique com ela & \\
\hline & RESP 7. ser respeitada & \\
\hline \multirow{8}{*}{ Similaridade } & Para você se tornar seguidor (a), uma blogueira de moda ..... & Autores \\
\hline & SIM 1. combinar com você & \multirow{7}{*}{$\begin{array}{l}\text { Shimp (2009); } \\
\text { Barbosa et al. } \\
(2014)\end{array}$} \\
\hline & SIM 2. ter faixa etária semelhante à sua & \\
\hline & SIM 3. ter etnia semelhante à sua & \\
\hline & SIM 4. publicar sobre marcas/produtos que parecem "feitas/os para você" & \\
\hline & SIM 5. ter o mesmo "gosto"/preferência que o seu & \\
\hline & SIM 6. abordar tópicos que despertem interesse & \\
\hline & SIM 7. abordar tópicos que se encaixem na sua realidade & \\
\hline Difusão da informação & Para você se tornar seguidor (a), uma blogueira de moda ..... & Autores \\
\hline
\end{tabular}


Gandra, C. F. A. O., Gosling, M. S., Vera, L. A. R., Vilela, B. A. (2018)

\begin{tabular}{|c|c|c|}
\hline \multirow[t]{4}{*}{ e de ideias } & DDI 1. conectar o (a) seguidor (a) a novas tendências. & \multirow{4}{*}{$\begin{array}{l}\text { Clarke e } \\
\text { Johnstone (2012) }\end{array}$} \\
\hline & DDI 2. difundir informações sobre produtos novos / recém-lançados. & \\
\hline & DDI 3. ajudar para que novas tendências ganhem força no cotidiano dos (as) seguidores (as) & \\
\hline & DDI 4. ser inovadora & \\
\hline \multirow{5}{*}{$\begin{array}{c}\text { Intenção de continuar } \\
\text { seguindo os blogs de } \\
\text { moda }\end{array}$} & Para você se tornar seguidor (a), uma blogueira de moda ..... & Autores \\
\hline & $\begin{array}{l}\text { INT 1. Quando quero saber sobre um novo assunto de moda, recorrer a blogs famosos é } \\
\text { minha primeira opção }\end{array}$ & \multirow[t]{4}{*}{$\begin{array}{l}\text { Hsu, Liu e Lee } \\
(2010)\end{array}$} \\
\hline & $\begin{array}{l}\text { INT 2. Eu sempre consulto blogs de moda antes de efetuar uma compra de artigos de } \\
\text { vestuário }\end{array}$ & \\
\hline & INT 3. Eu pretendo continuar seguindo blogs de moda & \\
\hline & INT 4. Eu pretendo seguir um número cada vez maior de blogs de moda & \\
\hline
\end{tabular}

Fonte: Elaborado pelos autores com o suporte de Shimp (2009) e Clarke e Johnstone (2012).

Para auxiliar a realização do trabalho, foram utilizados o software SPSS (Statistical Package for Social Sciences) e o software Smart-PLS 2.0. Em primeiro lugar, foi feita uma análise descritiva da amostra com o objetivo de oferecer uma descrição do perfil dos pesquisados. Após essa etapa, realizou-se o processo de verificação da existência de outliers univariados e multivariados, seguindo as recomendações de Hair, Anderson, Tatham \& Black (2009). A partir do teste do coeficiente $Z$, verificou-se que não houve outliers univariados. Em relação ao procedimento de verificação de outliers multivariados, não foram detectados outliers (medidos por meio do teste de Mahalanobis). Para esse teste, seguiram-se os parâmetros indicados por Hair Jr., Black, Babin $\&$ Anderson, R. E. (2014a) (2014a), que explicam que, para amostras grandes ( $n$ maior que 80 ), é melhor considerar como outliers multivariados os casos em que os valores forem acima de 3.

Posteriormente, foi realizada uma análise fatorial exploratória para identificar quais os principais atributos das blogueiras de moda na perspectiva dos seus seguidores (as) e, em seguida, uma análise de modelagem de equações estruturais no software Smart-PLS 2.0 para verificar quais os impactos das dimensões encontradas na intenção de as pessoas continuarem seguindo os blogs. A análise do modelo passa pela avaliação de medidas de validade e confiabilidade de modo a avaliar a consistência da forma de mensuração dos dados. Finalmente, analisam-se os indicadores que evidenciam a qualidade das relações teóricas apresentadas no modelo estrutural proposto.

\section{Análise dos Resultados e Discussão dos Resultados}

\section{Perfil da amostra}


Com o objetivo de descrever o perfil da amostra quanto ao gênero, ao estado civil, à faixa etária, à renda familiar mensal, ao nível de escolaridade e ao porte da cidade em que reside (por número de habitantes), realizou-se uma análise com a aplicação de estatística descritiva, especialmente mediante o uso de distribuição de frequências. A partir da análise dos resultados, foi possível traçar um perfil predominante dos respondentes, sendo este: do sexo feminino (96,5\%), com a idade entre 18 e 50 anos, com grau de instrução de ensino superior completo $(27,8 \%)$ e com curso superior incompleto $(26,3 \%)$, com renda mensal de até 2 salários mínimos $(34,4 \%)$ e de 3 a 5 salários mínimos $(32,8 \%)$.

\section{Análise fatorial exploratória}

A análise fatorial exploratória (AFE) foi realizada utilizando o método de extração de componentes principais e rotação oblíqua. O objetivo foi o de verificar as dimensões importantes dos endossantes de blogs de moda, na percepção dos seguidores. Por questões de ausência de evidências empíricas que justificassem a utilização dos dados do construto Respeito como uma medida adequada no modelo proposto, optou-se por não utilizar o construto na operacionalização do modelo estrutural.

Tabela 1 - Matriz de componentes.

\begin{tabular}{|c|c|c|c|c|c|}
\hline & \multicolumn{5}{|c|}{ Componentes } \\
\hline & 1 & 2 & 3 & 4 & 5 \\
\hline $\begin{array}{l}\text { CONF6. Para você se tornar seguidor (a), uma blogueira de moda } \\
\text { deve... [... passar credibilidade] }\end{array}$ &, 636 & & & & \\
\hline $\begin{array}{l}\text { CONF7. Para você se tornar seguidor (a), uma blogueira de moda } \\
\text { deve... [... não tentar manipular os/as seguidores/as }]\end{array}$ &, 536 & & & & \\
\hline $\begin{array}{l}\text { CONF10. Para você se tornar seguidor (a), uma blogueira de moda } \\
\text { deve... [... ser honesta] }\end{array}$ &, 838 & & & & \\
\hline $\begin{array}{l}\text { CONF11. Para você se tornar seguidor (a), uma blogueira de moda } \\
\text { deve... [... ser íntegra }]\end{array}$ & ,907 & & & & \\
\hline $\begin{array}{l}\text { RESP7. Para você se tornar seguidor (a), uma blogueira de moda } \\
\text { deve... [...saber se diferenciar] }\end{array}$ &, 713 & & & & \\
\hline $\begin{array}{l}\text { AF1. Para você se tornar seguidor (a), uma blogueira de moda } \\
\text { deve... [... ser bonita] }\end{array}$ & &, 792 & & & \\
\hline
\end{tabular}




\begin{tabular}{|c|c|c|c|c|}
\hline $\begin{array}{l}\text { AF4. Para você se tornar seguidor (a), uma blogueira de moda } \\
\text { deve... [... ficar bem (em termos de aparência) vídeos] }\end{array}$ & ,682 & & & \\
\hline $\begin{array}{l}\text { AF5. Para você se tornar seguidor (a), uma blogueira de moda } \\
\text { deve... [... seguir o padrão de beleza imposto pela mídia] }\end{array}$ & ,718 & & & \\
\hline $\begin{array}{l}\text { EXP2. Para você se tornar seguidor (a), uma blogueira de moda } \\
\text { deve... [...ser especialista nas marcas/produtos que promove] }\end{array}$ & &,- 640 & & \\
\hline $\begin{array}{l}\text { EXP3. Para você se tornar seguidor (a), uma blogueira de moda } \\
\text { deve... [...estar familiarizada com as marcas/produtos que promove] }\end{array}$ & &,- 918 & & \\
\hline $\begin{array}{l}\text { EXP9. Para você se tornar seguidor (a), uma blogueira de moda } \\
\text { deve... [...ter personalidade atraente] }\end{array}$ & &,- 965 & & \\
\hline $\begin{array}{l}\text { SIM1. Para você se tornar seguidor (a), uma blogueira de moda } \\
\text { deve... [...ter faixa etária semelhante à sua] }\end{array}$ & & & ,787 & \\
\hline SIM 2. ter faixa etária semelhante à sua & & &, 585 & \\
\hline $\begin{array}{l}\text { SIM4. Para você se tornar seguidor (a), uma blogueira de moda } \\
\text { deve... [...combinar com você] }\end{array}$ & & & ,678 & \\
\hline $\begin{array}{l}\text { SIM5. Para você se tornar seguidor (a), uma blogueira de moda } \\
\text { deve... [...abordar tópicos que se encaixem na sua realidade] }\end{array}$ & & & ,743 & \\
\hline SIM 7. abordar tópicos que se encaixem na sua realidade & & & ,678 & \\
\hline $\begin{array}{l}\text { DI1. Para você se tornar seguidor (a), uma blogueira de moda } \\
\text { deve... [...conectar o (a) seguidor (a) a novas tendências }]\end{array}$ & & & &, 882 \\
\hline $\begin{array}{l}\text { DI2. Para você se tornar seguidor (a), uma blogueira de moda } \\
\text { deve... [...difundir informações sobre produtos novos/recém- } \\
\text { lançados] }\end{array}$ & & & & ,433 \\
\hline $\begin{array}{l}\text { DDI3. Para você se tornar seguidor (a), uma blogueira de moda } \\
\text { deve... [...ajudar para que novas ideias ganhem força no cotidiano } \\
\text { dos (as) seguidores (as)] }\end{array}$ & & & & ,603 \\
\hline $\begin{array}{l}\text { DI4. Para você se tornar seguidor (a), uma blogueira de moda } \\
\text { deve... [...ser inovadora] }\end{array}$ & & & & ,737 \\
\hline
\end{tabular}

Método de Extração: Análise dos Componentes Principais

Métodos de Rotação: Oblimin com Normalização Kaiser.

Fonte: Dados do estudo, 2018

\section{Análise de modelagem de equações estruturais}

A avaliação do modelo proposto no artigo segue as recomendações sobre a aplicação da técnica de modelagem de equações estruturais em que primeiro se avaliam os modelos de mensuração por meio de análises de confiabilidade e de validade (agora em uma etapa quantitativa) de acordo com alguns parâmetros já estabelecidos. Posteriormente, deve-se fazer análise do modelo estrutural, ou das relações entre as variáveis latentes.

No modelo proposto, todas as variáveis latentes são reflexivas, portanto para se avaliar a qualidade de suas medidas foram utilizados os parâmetros de alpha de Cronbach e de confiabilidade composta, de confiabilidade dos indicadores e de variância média extraída para se avaliar a confiabilidade e a validade convergente dos indicadores com relação às variáveis latentes. Os parâmetros utilizados para avaliar a confiabilidade das medidas, segundo Hair Jr., 
Hult, Ringle \& Sarstedt (2014b), devem ser entre 0,7 e 0,9 para serem aceitáveis tanto para o alpha de Cronbach quanto para a confiabilidade composta.

A validade convergente diz respeito à extensão com que um indicador tem correlação positiva com outros indicadores do mesmo construto (Hair et al, 2014b). Para avaliar a validade convergente de construtos, utiliza-se a avaliação do AVE e das cargas externas dos indicadores. A variância explicada deve ser superior a 50\%, implicando que a variância compartilhada entre o construto e o indicador é maior do que a variância do erro. Isso quer dizer que a carga externa do indicador deve ser superior a 0,708 , já que esse número ao quadrado equivale a 0,5. No entanto, valores acima de 0,7 são aceitáveis (Hair et al, 2014b). A Tabela 2 aponta que os indicadores de confiabilidade e de validade convergente são aceitáveis e mostra que as medidas utilizadas são adequadas nesses parâmetros para medir os construtos estudados. A exceção existente foi o do indicador SIM07 que mostrou carga abaixo do parâmetro de 0,7 . Por haver ganhos nos índices de confiabilidade e de validade convergente, optou-se por excluir tal item.

Tabela 2 - Confiabilidade e validade convergente dos modelos de mensuração.

\begin{tabular}{|c|c|c|c|c|c|}
\hline Variável Latente & Indicadores & Cargas & AVE & $\begin{array}{l}\text { Alpha de } \\
\text { Cronbach }\end{array}$ & $\begin{array}{c}\text { Confiabilidade } \\
\text { Composta }\end{array}$ \\
\hline \multirow{5}{*}{ Confiabilidade } & CONF6 & 0,830 & \multirow{5}{*}{0,665} & \multirow{5}{*}{0,873} & \multirow{5}{*}{0,908} \\
\hline & CONF7 & 0,760 & & & \\
\hline & CONF9 & 0,803 & & & \\
\hline & CONF10 & 0,829 & & & \\
\hline & CONF11 & 0,852 & & & \\
\hline \multirow{3}{*}{ Atração física } & $\mathrm{AF} 1$ & 0,867 & \multirow{3}{*}{0,684} & \multirow{3}{*}{0,769} & \multirow{3}{*}{0,866} \\
\hline & $\mathrm{AF} 4$ & 0,795 & & & \\
\hline & AF5 & 0,818 & & & \\
\hline \multirow{3}{*}{$\begin{array}{c}\text { Expertise (conhecimento } \\
\text { específico) }\end{array}$} & EXP2 & 0,799 & \multirow{3}{*}{0,758} & \multirow{3}{*}{0,840} & \multirow{3}{*}{0,904} \\
\hline & EXP3 & 0,905 & & & \\
\hline & EXP9 & 0,904 & & & \\
\hline \multirow[b]{2}{*}{ Similaridade } & SIM1 & 0,854 & \multirow[b]{2}{*}{0,640} & \multirow[b]{2}{*}{0,876} & \multirow[b]{2}{*}{0,848} \\
\hline & SIM2 & 0,772 & & & \\
\hline
\end{tabular}


Gandra, C. F. A. O., Gosling, M. S., Vera, L. A. R., Vilela, B. A. (2018)

\begin{tabular}{|c|c|c|c|c|c|}
\hline & SIM4 & 0,818 & & & \\
\hline & SIM5 & 0,752 & & & \\
\hline \multirow{4}{*}{$\begin{array}{c}\text { Difusão da informação } \\
\text { e de ideias }\end{array}$} & DDI1 & 0,841 & \multirow{4}{*}{0,606} & \multirow{4}{*}{0,784} & \multirow{4}{*}{0,860} \\
\hline & DDI2 & 0,763 & & & \\
\hline & DDI 3 & 0,740 & & & \\
\hline & DDI4 & 0,765 & & & \\
\hline \multirow{4}{*}{$\begin{array}{c}\text { Intenção de continuar } \\
\text { seguindo }\end{array}$} & INT1 & 0,828 & \multirow{4}{*}{0,674} & \multirow{4}{*}{0,838} & \multirow{4}{*}{0,892} \\
\hline & INT2 & 0,846 & & & \\
\hline & INT3 & 0,744 & & & \\
\hline & INT4 & 0,861 & & & \\
\hline
\end{tabular}

Fonte: Dados do estudo, 2018.

A validade discriminante é a extensão em que cada construto é único e verdadeiramente diferente dos outros construtos em padrões empíricos (Hair et al, 2014b). Para se avaliar a validade discriminante dos construtos reflexivos, dois critérios foram utilizados. Primeiro, foi utilizado o critério de cargas cruzadas que indica que a carga externa de cada construto associada a ele deve ser maior do que todas as suas cargas relacionadas a outros construtos. A avaliação das cargas cruzadas nos constructos reflexivos demonstrou não haver problema de validade discriminante.

O segundo critério de avaliação de validade discriminante é a comparação da correlação entre as variáveis latentes com o valor da raiz quadrada do valor da AVE de cada construto, tal critério é denominado, critério de Fornell-Larcker. Nota-se que tanto a partir do teste de cargas cruzadas como a partir do critério de Fornell-Larcker, mais rigoroso, pode-se afirmar que houve validade discriminante de todos os constructos do modelo teórico da pesquisa.

Segundo as medidas de qualidade do modelo de mensuração, foi possível atestar que a proposta para se operacionalizar as medidas para o modelo teórico em questão foi validada de forma empírica. Assim, após a análise do modelo de mensuração, foi realizada a análise do modelo estrutural, utilizando o software Smart-PLS 2.0. Foi gerado o seguinte modelo apresentado com as respectivas variáveis observadas e escores gerados a partir do algoritmo do SmartPLS 2.0. 
Figura 6 - Modelo estrutural da pesquisa.

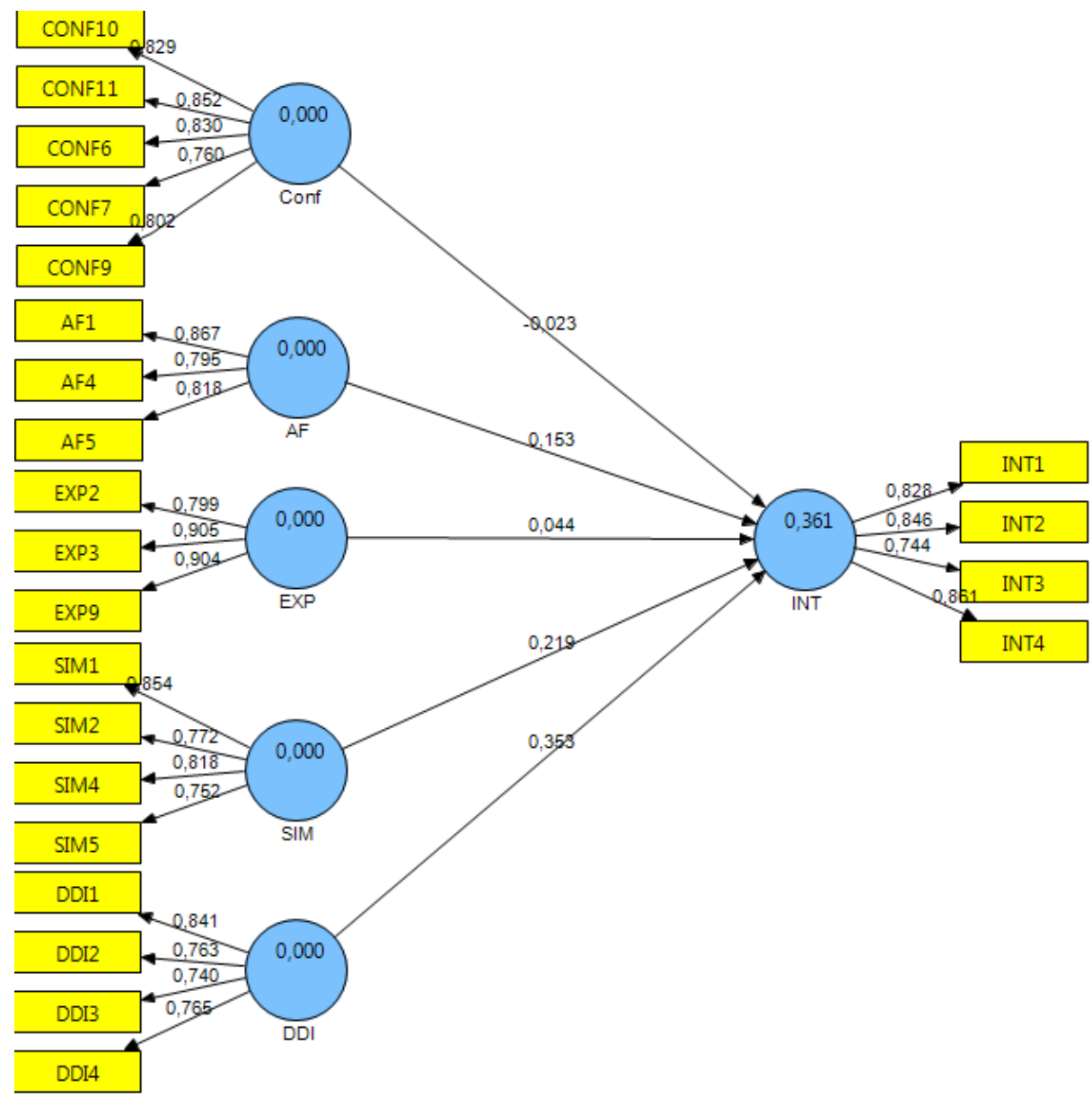

Fonte: Dados do estudo, 2018.

Após realizar a avaliação de colinearidade no SPSS, notou-se não haver problemas de colinearidade entre os construtos como pode ser verificado na Tabela 3.

Tabela 3 - Teste de colinearidade.

\begin{tabular}{|l|r|r|}
\hline \multirow{2}{*}{ Modelo } & \multicolumn{2}{|c|}{ Estatísticas de colinearidade } \\
\cline { 2 - 3 } & \multicolumn{2}{|c|}{ Tolerância } \\
\hline AF &, 633 & VIF \\
\hline CONF &, 599 & 1,581 \\
\hline DDI &, 497 & 1,669 \\
\hline EXP &, 615 & 1,011 \\
\hline SIM &, 627 & 1,595 \\
\hline
\end{tabular}

Fonte: Dados do estudo, 2018. 
Após os testes de colinearidade, deve-se entender as relações do modelo estrutural que representam as relações das hipóteses entre os construtos. Os valores dos efeitos de um construto sobre outros são padronizados entre -1 e +1 , sendo quanto mais os valores forem próximos a 0, menor a significância das relações (Hair et al., 2014b). Já o coeficiente de determinação $\left(\mathrm{R}^{2}\right)$ varia entre 0 e 1 , sendo o quanto mais os valores forem próximos a 1 , maior o poder de previsão das variáveis endógenas. Os coeficientes devem ser avaliados pelos parâmetros de valores de 0,$19 ; 0,33$ e 0,67 , representando respectivamente poder de previsão fraco, moderado e substancial (Henseler, Ringle \& Sinkovics, 2009).

Segundo a análise no modelo proposto, o coeficiente de determinação encontrado foi de 0,361 podendo ser classificado como relativamente moderado, de acordo com esse critério. $\mathrm{O}$ valor do $\mathrm{R}^{2}$ relativamente baixo, porém satisfatório, pode ser explicado pelo fato de que o estudo é exploratório e avalia um modelo ainda não testado.

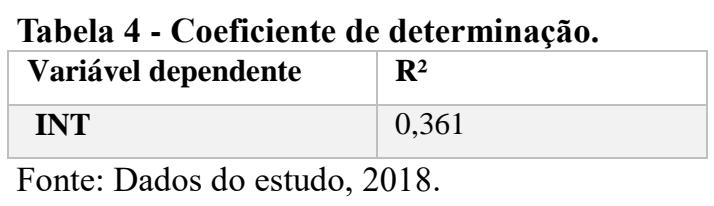

Os coeficientes de caminho foram estimados no modelo e avaliados em termos de significância via bootstraping, que permite a verificação por meio do teste T. Os valores críticos são 2,57 - nível de significância de 1\%; 1,96 - nível de significância de 5\%; 1,65 nível de significância de 10\%. Quando o valor do teste T da saída do bootstraping é superior aos valores críticos, pode-se assumir que os efeitos são significativos. Na pesquisa, foi rodado bootstraping simulando 5.000 subamostras como sugerido por Hair et al. (2014b).

No estudo, pôde-se verificar a relação entre as variáveis com o nível de significância de $1 \%$, entre Difusão da Informação e intenção de continuar seguindo, e entre Similaridade e intenção de continuar seguindo confirmando as hipóteses de uma relação diretamente proporcional entre as variáveis. Já a relação entre Atração Física e intenção de continuar seguindo foi confirmada com nível de significância de 5\%. As outras relações testadas não foram significativas segundo o teste. 
Tabela 5 - Coeficientes de caminho e níveis de significância.

\begin{tabular}{|l|r|r|}
\hline & T Statistics (|O/STERR|) & Significância \\
\hline $\mathbf{A F} \rightarrow$ INT & 2,2498 & $5 \%$ \\
\hline $\mathbf{C O N F} \rightarrow$ INT & 0,3381 & $\mathrm{~N} / \mathrm{S}$ \\
\hline $\mathbf{D D I} \rightarrow$ INT & 4,5799 & $1 \%$ \\
\hline $\mathbf{E X P} \rightarrow$ INT & 0,5873 & $\mathrm{~N} / \mathrm{S}$ \\
\hline $\mathbf{S I M} \rightarrow$ INT & 3,0994 & $1 \%$ \\
\hline
\end{tabular}

Fonte: Dados do estudo, 2018

Figura 6 - Resultado final do teste de hipóteses.

\begin{tabular}{|c|c|c|}
\hline \multicolumn{3}{|c|}{ Hipóteses } \\
\hline H1 & A Confiabilidade tem relação direta e positiva com a intenção de continuar seguindo. & Não suportada \\
\hline H2 & A Expertise tem relação direta e positiva com a intenção de continuar seguindo. & Não suportada \\
\hline H3 & A Atração Física tem relação direta e positiva com a intenção de continuar seguindo. & Suportada \\
\hline H4 & O Respeito tem relação direta e positiva com a intenção de continuar seguindo. & Não suportada \\
\hline H5 & A Similaridade tem relação direta e positiva com a intenção de continuar seguindo. & Suportada \\
\hline H6 & $\begin{array}{l}\text { A Difusão de Informações e Ideias tem relação direta e positiva com a intenção de continuar } \\
\text { seguindo. }\end{array}$ & Suportada \\
\hline
\end{tabular}

Fonte: Dados do estudo, 2018

Com relação ao tamanho do efeito de cada variável independente sobre o coeficiente de determinação da variável dependente, foi calculado o valor do coeficiente com e sem cada variável independente no modelo para se estimar o tamanho do efeito para cada variável. Segundo Hair et al. (2014b), os parâmetros são 0,02; 0,15; e 0,35, representando respectivamente efeitos pequenos, médios e grandes. Os efeitos do estudo que se mostraram significativos foram considerados pequenos como mostrado na tabela 6 , o que pode indicar a magnitude dos efeitos sobre a variável dependente do estudo.

Tabela 6 - Tamanho dos efeitos $f^{2}$.

\begin{tabular}{|c|c|c|}
\hline & $\mathbf{f}^{2}$ & Tamanho do efeito \\
\hline $\mathbf{A F}$ & 0,023 & Pequeno \\
\hline CONF & 0,002 & NS \\
\hline DDI & 0,091 & Pequeno \\
\hline EXP & 0,003 & NS \\
\hline
\end{tabular}




\begin{tabular}{|l|r|l|}
\hline SIM & 0,047 & Pequeno \\
\hline
\end{tabular}

Fonte: Dados do estudo, 2018.

Para o construto endógeno Intenção de continuar seguindo, o modelo apresentou relevância preditiva, revelando o valor de $\mathrm{Q}^{2}$ maior que 0 , sendo de 0,241 . Segundo o critério de tamanho do efeito com relação à relevância preditiva $\left(\mathrm{q}^{2}\right)$, apenas as variáveis Difusão de informação e Similaridade se mostraram como significativas, mas com tamanho de efeito pequeno, demonstrando sob esse critério que talvez as variáveis do estudo ainda necessitam de refinamento e outros estudos confirmatórios para serem utilizados com mais segurança, medindo a relação proposta entre as variáveis latentes independentes e a variável dependente do estudo.

Tabela 7 - Tamanho dos efeitos $q^{2}$.

\begin{tabular}{|l|r|l|}
\hline & $\mathbf{q}^{\mathbf{2}}$ & Tamanho do efeito \\
\hline AF & 0,014 & NS \\
\hline CONF & $-0,001$ & NS \\
\hline DDI & 0,051 & Pequeno \\
\hline EXP & 0,002 & NS \\
\hline SIM & 0,025 & Pequeno \\
\hline
\end{tabular}

Fonte: Dados do estudo, 2018.

De modo geral, as hipóteses suportadas foram que a Atração Física, a Similaridade e a Difusão de Informações têm relação direta e positiva com a intenção de continuar seguindo os blogs de moda. O fato de a Atração Física ter sido uma hipótese suportada no presente estudo encontra sustentação na literatura a partir do que Shimp (2009) expôs sobre tal atributo ser um importante aspecto em vários relacionamentos com o endosso. Para o autor, os endossantes atraentes fisicamente geram avaliações mais favoráveis no anúncio e nas marcas anunciadas. Este resultado também confirma o que Patel (2009) apontou sobre a importância da celebridade escolhida ser bonita e atraente. Tal achado também apresenta semelhança com os resultados do estudo qualitativo de Barbosa et al. (2014), que evidenciaram que a Atração Física foi considerada essencial pelas entrevistadas por causa do contexto em que as blogueiras de moda estão inseridas no qual a imagem é bem valorizada. 
O resultado de que a Similaridade tem relação direta com a intenção de continuar seguindo apresenta sustentação na literatura na medida em que Kent (2008) expõe, por exemplo, que os seguidores/leitores podem ser indivíduos que têm interesses ou visões de mundo semelhantes às dos blogueiros. Tal resultado também é parecido com os achados do estudo qualitativo de Barbosa et al. (2014) cujos sujeitos de pesquisa evidenciaram que a Similaridade foi um dos atributos mais relevantes para a legitimação das blogueiras de moda.

A hipótese suportada acerca da Difusão de Informações corrobora o que Clarke e Johnstone (2012) expuseram sobre o poder da comunicação boca a boca online dos blogs de moda. Para os autores, os blogs têm se tornado uma importante ferramenta no contexto da indústria fashion. Tal achado do presente artigo também está em sintonia com o que Kent (2008) afirmou sobre a capacidade dos blogs de conectar as pessoas com interesses semelhantes através da Internet. Assim, o resultado deste estudo sobre as blogueiras de moda tem semelhança com os resultados do estudo qualitativo realizado por Clarke e Johnstone (2012) que revelaram que alguns blogs podem ser visto como "hubs" (cabos) que operam no âmbito da rede de blogs de moda. Nessa rede acontece a difusão de informação e ideias, semelhante à difusão de um produto dentro do mercado.

O fato de a Confiabilidade não ter sido uma hipótese suportada apresenta semelhança com os resultados dos estudos de Ohanian (1991) e de Hakimi, Abedniya e Zaeim (2011), nos quais o constructo também não foi significativo. Já o fato de a Expertise não ter sido uma hipótese suportada contraria o resultado do estudo de Ohanian (1991), que encontrou que a Expertise dos endossantes de marca (atores, no caso do estudo) teve um impacto significante na intenção de compra dos consumidores. $\mathrm{O}$ resultado do presente estudo sobre o contexto dos blogs de moda indica, portanto, que a Credibilidade não foi um atributo influente, já que, segundo Shimp (2009) tanto a Confiabilidade quanto o Conhecimento Específico são dimensões da Credibilidade. Tal achado contrariou, assim, o que Alsmadi (2006) afirmou sobre a Credibilidade ser considerada como a mais importante razão para selecionar uma celebridade como endossante de marca. 


\section{Conclusões}

Este trabalho, de caráter exploratório, teve o objetivo de verificar quais foram os atributos importantes das blogueiras de moda que contribuem para a intenção das pessoas de continuarem seguindo os blogs. Para tanto, utilizou-se como base teórica os atributos (Confiabilidade, Expertise, Atração Física, Respeito e Similaridade) apontados pelo modelo TEARS, desenvolvido por Shimp (2009), e acrescentou-se um construto denominado de Difusão da Informação e Ideias, extraído do estudo de Clarke e Johnstone (2012).

Outros estudos que também se basearam em escalas de pessoas referência (ou celebridades) que influenciam consumidores trazem algumas similaridades e diferenças com relação a presente proposta. Ohanian (1990) desenvolveu a escala apenas com o conceito de confiabilidade, atração física e expertise como fundamentais para celebridades que endossam determinados produtos. Outros autores utilizaram ainda os construtos de similaridade, popularidade e relevância da celebridade com relação aos produtos endossados enquanto fatores (Bergstrom \& Skarfstad, 2004; Ericsson \& Hakansson, 2005; Gupta, Kishor \& Verma, 2017). Assim como esses trabalhos citados, o presente artigo buscou validar escalas e construtos do modelo TEARS, contribuindo teoricamente para reformulá-lo, apresentando novas dimensões a serem incorporadas ou substituídas. Além disso, apresentou a extensão da capacidade preditiva do modelo representada pelo construto intenção de se continuar seguindo as blogueiras (relacionado ao "consumo" do conteúdo e serviço por elas apresentado).

A análise fatorial exploratória sobre os dados coletados no survey indicou cinco fatores: Confiabilidade, Expertise, Atração Física, Similaridade e Difusão da Informação e Ideias. Verificou-se, porém, que o construto Respeito não se revelou uma medida adequada no modelo proposto e, por isso, optou-se por não utilizar o construto na operacionalização do modelo estrutural.

Em seguida, propôs-se um modelo estrutural considerando as variáveis latentes exógenas Confiabilidade, Expertise, Atração Física, Similaridade e Difusão da Informação e Ideias. Na avaliação dos modelos de mensuração, encontrou-se validade tanto discriminante como convergente para todas as variáveis, o que indica boa adequação das escalas quando avaliados os construtos individualmente. 
$\mathrm{Na}$ avaliação do modelo estrutural foi testada a validade preditiva de tais variáveis com relação à variável Intenção de Continuar Seguindo. O modelo proposto demonstrou um poder de explicação da variável endógena em nível moderado. As hipóteses de que a Difusão da Informação, a Atração Física e a Similaridade apresentam relação direta e positiva com a intenção de continuar seguindo os $b \operatorname{logs}$ foram suportadas no estudo. Já as variáveis Conhecimento Específico (Expertise) e Confiabilidade não demonstraram relação com intenção de continuar seguindo. Em princípio, tal resultado pode parecer inconsistente com a teoria, mas pode ser interessante aprofundar a análise e inferir que a Confiabilidade (nível de confiança que a blogueira passa aos seguidores) bem como o Conhecimento Específico podem não ser realmente atributos importantes para os seguidores. Esta inferência pode ser feita ao se considerar que as blogueiras não são estilistas, os quais seriam figuras em que a confiabilidade e expertise seriam, de certa forma, incontestavelmente importantes.

Por outro lado, ser criativa para difundir tendências, ter um alto grau de identidade com os seguidores e ser fisicamente atraente são importantes. Isso faz sentido, na medida em que pesquisas anteriores mostram que seguidores buscam saber das tendências e se espelhar nas blogueiras e, portanto, esperam "parecer" com pessoas consideradas bonitas, na moda, antenadas.

O artigo contribuiu teoricamente para a construção e validação de escalas de um modelo de atributos de endossantes de blogs de moda para seguidores, inspirado no modelo teórico de Shimp (2009). O estudo pôde contribuir para a introdução de uma variável nova ao modelo TEARS - Difusão da Informação e Ideias, ampliando-o. Nesse sentido, propôs-se uma revisão da teoria que embasa o modelo TEARS, aplicando-a no contexto dos blogs de moda.

A proposta de modelo teórico desenvolvida no presente estudo foi verificada empiricamente e percebeu-se que o modelo TEARS demonstrou baixa consistência quando relacionado à intenção de continuar seguindo. A principal consequência da aplicação do modelo foi o fato de confirmar a relação positiva de influência da Difusão de Informação, da Atração Física e da Similaridade sobre a Intenção de Continuar seguindo.

Isso quer dizer que, quanto mais as blogueiras de moda forem formadoras de opinião e difusoras de ideias, maior será a possibilidade de seus (suas) seguidores (as) / leitores (as) terem a intenção de continuarem seguindo. Tal hipótese suportada no modelo reforça a ideia trazida por Clarke e Johnstone (2012) de que a difusão de informações e ideias é uma 
característica significativa no que tange aos blogueiros (as) de moda. Para os autores, os (as) blogueiros (as) de moda têm grande poder de influência como líderes de opinião e podem ser vistos (as) como conectores e difusores de tendências. Assim, é possível concluir que conectar os seguidores a novas tendências, difundir informações sobre produtos novos/recém-lançados, ser inovadora e contribuir para que novas tendências ganhem força no cotidiano dos seguidores são fatores importantes para que os seguidores tenham a intenção de continuar seguindo os blogs.

Outra conclusão do presente artigo é que, quanto mais as blogueiras possuem atributos relacionados aos atrativos físicos, maior pode ser a intenção de as pessoas continuarem seguindo-as. Isso confirma a ideia de Shimp (2009) de que os endossantes atraentes fisicamente geram avaliações mais favoráveis no anúncio e nas marcas anunciadas. Nesse sentido, ser bonita, ficar bem (no que diz respeito à aparência) em vídeos e seguir um padrão de beleza imposto pela mídia correspondem a aspectos que são valorizados pelos (as) seguidores (as). Tal resultado do estudo apresenta sintonia com o que Barbosa et al. (2014) afirmaram em relação ao fato de a Atração Física ser um construto considerado essencial por causa do contexto em que as blogueiras de moda estão inseridas e no qual a imagem é muito valorizada.

Além disso, verificou-se que, quanto mais as blogueiras demonstrarem similaridade com as leitoras, mais os seguidores podem ter intenção em continuar seguindo-as. Tal conclusão confirma a ideia abordada por Shimp (2009) de que as pessoas tendem a aprovar mais quem compartilha com elas algumas características ou aspectos em comum. Dessa forma, quando os (as) seguidores (as) consideram que as blogueiras combinam com o seu estilo e publicam sobre produtos e marcas que parecem ser feitos para seus leitores, existe uma aprovação maior do trabalho das blogueiras e uma possibilidade maior de haver um interesse em continuar seguindo os blogs. Além disso, este estudo indicou que ter faixa etária semelhante à das blogueiras e ter os mesmos gostos e preferências são aspectos importantes do construto Similaridade na visão dos seguidores.

Pode-se identificar enquanto limitação do estudo a baixa aderência do modelo completo proposto quando aplicado sob condições de explicação de outras variáveis. No entanto, essa baixa aderência pode ser explicada pela ausência de referências anteriores sobre a aplicabilidade de tal modelo teórico, que ainda mostrou necessidade de refinamento. É 
possível que, com novas amostragens e uma revisão das escalas propostas, o modelo possa apresentar mais relações significativas dentro da mesma proposta.

Como sugestão para estudos futuros, indica-se a utilização das escalas desenvolvidas na presente pesquisa em outros contextos. Outra possibilidade seria a ampliação do modelo, testando relações com outros conceitos clássicos do marketing ou mesmo relações mais específicas que possam ser aplicadas na prática do contexto de blogs de moda.

\section{Referências}

Ali, S. (2011). The optimum celebrity-brand fit: A study of two models. Thesis (Master Business) - Univertett Van Amsterdam, Amsterdam.

Alsmadi, S. (2006). The power of celebrity endorsement in brand choise behavior: an empirical study of consumer attitudes. Journal of Accounting - Business \& Management, 13, 69-84.

Barbosa, O. T., Kovacs, M. H., Farias, S. A., Melo, F. V. S. \& Souza, A. G. (2014) Credibilidade e atratividade dos endossantes de blogs de moda na visão das seguidoras. Revista Design, Inovação e Gestão Estratégica - REDIGE, 5, 1.

Bergstrom, C. \& Skarfstad, R. (2004). Celebrity endorsement. Case study of J. Lindeberg. Lulea University of Technology, Sweden. Recuperado de www. epubl. 1tu. se.

Clarke, R. \& Johnstone, M. (2012). The influence of fashion blogs on consumers+. In: Academy of Marketing UK Conference Proceedings.

Dearstyne, B. W. (2005). Blogs: The New Information Revolution? Information Management Journal, 39 (3), 38-44.

Comscore (2015) Digital future in focus Brazil. Recuperado de $<$ http://www.comscore.com/Insights/Presentations-and-Whitepapers/2015/2015-BrazilDigital-Future-in-Focus $>$.

Erdogan, B. Z. (1999) Celebrity endorsement: A literature review. Journal of Marketing Management, 41(3), 291-314. 
Erdogan, B.Z. \& Baker, M.J (2000). Towards a practitioner-based model of selecting celebrity endorsers. International Journal of Advertising, 19(1), 25-42.

Ericsson, L. \& Håkansson, E. (2005). Athletes as celebrity endorsers: case studies from Sweden. Disponível em: diva-portal.org.

Falsarella, C. R. B. M., de Oliveira, J. H. C. \& Giraldi, J. D. M. E. (2017). The Influence of celebrity endorsement on visual attention: An eye-tracking study in Brazil. Academy of Marketing Studies Journal, 21(1).

Felix, R. \& Borges, A. (2014). Celebrity endorser attractiveness, visual attention and implications for ad attitudes and brand evaluations: A replication and extension. Journal of Brand Management, 21(7-8), 579-593.

Freire, R.; Behling, H. P. \& Reinert, J. (2010). Endosso de celebridades: uma análise baseada na complementaridade de modelos teóricos. In Anais... XI Congresso de Ciências da Comunicação na Região Sul - Novo Hamburgo - RS (vol. 17).

Friedman, H. \& Friedman, L. (1979). Endorser effectiveness by product type. Journal of Advertising Research, 19(5), 63-71.

Goldsmith, R. E., Lafferty, B. A. \& Newell, S. J. (2000). The impact of corporate credibility and celebrity credibility on consumer reaction to advertisements and brands. Journal of Advertising, 29(3), 43-54.

Gupta, R., Kishor, N. \& Verma, D. P. S. (2017). Construction and validation of a fivedimensional celebrity endorsement scale: introducing the pater model. British Journal of Marketing Studies, 5(4), 15-35.

Hair Jr., J., Anderson, R. E., Tatham, R. L. \& Black, W. C. (2009). Análise multivariada de dados (6a ed.). Porto Alegre: Bookman.

Hair Jr., H., Black, W. C., Babin, B. J, \& Anderson, R. E. (2014a). Multivariate Data Analysis. Harlow: Pearson.

Hair Jr., J. F., Hult, G. T. M., Ringle, C. M., \& Sarstedt, M. (2014b). A Primer on Partial Least Squares Structural Equation Modeling (PLS-SEM). Los Angeles: Sage. 
Hakimi, B.Y., Abedniya, A. \& Zaeim, M. N. (2011). Investigate the impact of celebrity endorsement on brand images. European Journal of Scientific Research, 58(1), 116-32

Henseler, J., Ringle, C. M. \& Sinkovics, R. R. (2009). The use of partial least squares path modeling in international marketing. Advances in International Marketing, 20, 277319.

Huang, C., Shen, Y., Lin, H. \& Chang, S. (2007). Bloggers' Motivations and Behaviors: A Model. Journal of Advertising Research, 47 (4).

Kaplan, A. M. \& Haenlein., M. (2010). Users of the world, unite! the challenges and opportunities of social media. Business Horizons, 53(1), 59-68.

Kent, M. L. (2008). Critical analysis of blogging in public relations. Public Relations Review, $34,32-40$.

Ladeira, W. J., Araújo, C. F., Santini, F. O. \& Henz, M. M. (2015). Endosso de celebridades e intenção de compra de chuteiras . Revista Pretexto, 16(4), 11-28.

Leitão, N. R. (2009). Interatividade: Análise de recepção de público nos blogs de moda. Brasília: UniCEUB.

McCracken, G. (1989). Who is the celebrity endorser? Cultural foundations of the endorsement process. Journal of Consumer Research, 16(3), 310-321.

Ohanian, R. (1990). Construction and validation of a scale to measure celebrity endorsers' perceived expertise, trustworthiness, and attractiveness. Journal of advertising, 19(3), $39-52$.

- (1991). The impact of celebrity spokesperson's perceived image on consumers intention to purchase. Journal of Advertising Research, 31(1), 46-52.

Patel, P. (2009). Impact of celebrity endorsement on brand acceptance. The Icfai University Journal of Consumer Behavior, 4(1).

Pringle, H. \& Binet, L. (2005). How marketers can use celebrities to sell more effectively. Journal of Consumer Behavior, 4(3), 201-214. 
Sarturi, L. \& Cerqueira, C. (2017). Mulheres, empoderamento e autoestima: A influência dos blogs de moda na identidade plus size. Revista Gênero \& Direito, 6(1).

Sheu, J. B. (2010). A hybrid dynamics forecast model for analyzing celebrity endorsement effects on consumer attitudes. Mathematical and Computer Modelling, 52(9-10), 15541569.

Shimp, T. A. (2009). Comunicação integrada de marketing: propaganda e promoção (7a ed.). Porto Alegre: Bookman.

Schneider, T. \& Pereira, L. P. (2015). As representações do consumo e da identidade nos principais blogs de moda do país. Revista Moda Palavra e Periódico, 8(15), 249-268.

Waldt, D. V. D.; Van Loggerenberg, M.; \& Wehmeyer, L. (2009). Celebrity endorsements versus created spokespersons in advertising: A survey among students. South African Journal of Economic and Management Sciences. 100-114.

Zanette, M. C. (2012). Commercial interventions in blogs through new influentials. In: Academy of Marketing UK Conference Proceedings.

Zanette, M. C., Brito, E. P. Z. \& Coutinho, M. (2013). New influentials: An exploratory study on blogs. Journal of Direct, Data and Digital Marketing Practice, 15(1), 36-46. 